Published in final edited form as:

Clin Cancer Res. 2012 March 1; 18(5): 1201-1206. doi:10.1158/1078-0432.CCR-11-0641.

\title{
Molecular Pathways: Beta-adrenergic signaling in cancer
}

\author{
Steven W. Cole ${ }^{1}$ and Anil K. Sood ${ }^{2}$ \\ ${ }^{1}$ Division of Hematology-Oncology, Department of Medicine, UCLA School of Medicine, Jonsson, \\ Comprehensive Cancer Center, Norman Cousins Center and UCLA Molecular Biology Institute \\ ${ }^{2}$ Departments of Gynecologic Oncology and Cancer Biology, and Center for RNA Interference \\ and Non-Coding RNA, MD Anderson Cancer Center, Houston, TX
}

\begin{abstract}
$\beta$-adrenergic signaling has been found to regulate multiple cellular processes that contribute to the initiation and progression of cancer, including inflammation, angiogenesis, apoptosis/anoikis, cell motility and trafficking, activation of tumor-associated viruses, DNA damage repair, cellular immune response, and epithelial-mesenchymal transition. In several experimental cancer models, activation of the sympathetic nervous system promotes the metastasis of solid epithelial tumors and the dissemination of hematopoietic malignancies via $\beta$-adrenoreceptor-mediated activation of PKA and EPAC signaling pathways. Within the tumor microenvironment, $\beta$-adrenergic receptors on tumor and stromal cells are activated by catecholamines from local sympathetic nerve fibers (norepinephrine) and circulating blood (epinephrine). Tumor-associated macrophages are emerging as key targets of $\beta$-adrenergic regulation in several cancer contexts. Sympathetic nervous system regulation of cancer cell biology and the tumor microenvironment has clarified the molecular basis for long-suspected relationships between stress and cancer progression and now suggest a highly leveraged target for therapeutic intervention. Epidemiologic studies have linked the use of $\beta$-blockers to reduced rates of progression for several solid tumors, and pre-clinical pharmacologic and biomarker studies are now laying the groundwork for translation of $\beta$-blockade as a novel adjuvant to existing therapeutic strategies in clinical oncology.
\end{abstract}

\section{Background}

The $\beta$-adrenergic signaling pathway (Figure 1) mediates sympathetic nervous system (SNS)induced fight-or-flight stress responses $(1,2)$. SNS neural fibers innervate virtually every major organ system of the body and can release micro-molar concentrations of the catecholamine neurotransmitter norepinephrine (NE) into target tissues in response to physiological, psychological, and environmental threats to homeostasis (1-3). Acute SNS activation also elevates catecholamine levels in circulating blood via the release of epinephrine (E) from chromaffin cells of the adrenal medulla and NE spill-over from vascular neuro-muscular junctions (1-3). Acute stress responses can elevate NE and E levels by $>10$-fold within seconds, but basal levels also fluctuate tonically over time in response to organismic and environmental conditions (1-3). In addition to central nervous system (CNS) control of general SNS neural outflow, local regulatory processes also influence SNS nerve fiber activity and catecholamine release and degradation. As a result, NE and E concentrations can differ substantially in solid tissues versus blood, as well as across different tissue environments at the same point in time (1-3).

The biological effects of $\mathrm{NE}$ and $\mathrm{E}$ are mediated by $\alpha_{1^{-}}, \alpha_{2^{-}}$, and $\beta$-adrenergic receptor families which show distinct patterns of tissue distribution and signal through distinct biochemical pathways $(3,4)$. The three subtypes of $\beta$-adrenergic receptor, $\beta_{1}, \beta_{2}$, and $\beta_{3}$, are present at many sites of tumor growth and metastasis such as the brain, lung, liver, kidney, adrenal gland, breast, ovary, prostate, lymphoid tissues, bone marrow, and vasculature. $\beta$ - 
adrenergic signaling regulates the biological activity of several cancer-relevant cell types including epithelial cells, vascular myocytes and pericytes, adipocytes, fibroblasts, neural/ glial cells, and most lymphoid and myeloid immune cells $(3,4)$. Ligation of $\beta$-receptors by $\mathrm{NE}$ and $\mathrm{E}$ activates the $\mathrm{G}_{\alpha \mathrm{s}}$ guanine nucleotide-binding protein to stimulate adenylyl cyclase synthesis of cyclic $3^{\prime}-5^{\prime}$ adenosine monophosphate (cAMP). The resulting transient cAMP flux can regulate a diverse array of cellular processes via two major downstream effector systems (Figure 1).

One cAMP effector involves activation of protein kinase A (PKA), which subsequently phosphorylates serine or threonine residues on target proteins that bear PKA-receptive amino acid motifs (e.g., R-R-X-[S/T]-Y, where $\mathrm{R}=$ arginine, $\mathrm{S}=$ serine, $\mathrm{T}=$ threonine, $\mathrm{X}=$ any amino acid, $\mathrm{Y}=$ hydrophobic amino acid). PKA regulates a wide variety of cellular processes ranging from general metabolism and growth to cell-specific processes such as differentiation, morphology, motility, secretion, neurotransmission, and gene transcription. Gene expression effects are mediated by PKA-induced phosphorylation of transcription factors such as the cAMP Response Element Binding Protein/Activating Transcription Factor (CREB/ATF) family, which collectively engage approximately $20 \%$ of human genes $(5,6)$. PKA-induced transcriptional alterations often promote cell differentiation at the expense of proliferation, and coordinate transcriptome-wide responses to stress or homeostatic perturbation (5). PKA also activates the $\beta$-adrenergic receptor kinase (BARK), which subsequently induces $\beta$-arrestin to transiently desensitize further $\beta$ receptor signaling and activate the Src/Ras/MAPK pathway (7). Recent work also shows that PKA can directly activate Src (A. Sood, unpublished data).

A second major cAMP effector involves the guanine nucleotide Exchange Protein activated by Adenylyl Cyclase (EPAC) (8). EPAC activates the Ras-like guanine triphosphatase Rap1A, which in turn stimulates downstream effectors B-Raf, MEK1/2, and ERK1/2. In addition to the well-known effects of the MAP kinase pathway on cell growth and proliferation, EPAC signaling accounts for many cAMP-induced effects on cell morphology, motility, and secretion dynamics. EPAC's effects can be distinguished from those of PKA through pharmacologic agonists and molecular manipulations (e.g., targetspecific siRNA). Although some overlaps occur, $\beta$-adrenergic influences on inflammation, angiogenesis, and invasion appear to be mediated predominately by PKA induction of genes encoding cytokines and growth factors, whereas EPAC induces complementary but distinct effects on cell morphology and motility.

\section{$\beta$-adrenergic regulation of tumor biology}

Studies of $\beta$-adrenergic influence on tumor biology were motivated by epidemiologic observations associating stressful life circumstances with accelerated progression of incident cancers $(9,10)$ and studies linking the use of $\beta$-adrenergic antagonists (" $\beta$-blockers") with reduced disease progression (11-15). Epidemiologic studies find the most consistent relationships between stressful conditions and progression of already-incident tumors, and relatively little data suggest that stress affects the initial incidence of cancer $(9,10)$. In vivo laboratory models also find the most consistent effects of experimentally imposed stress on xenograft and syngeneic tumor models (i.e., already initiated tumors) $(16,17)$, whereas effects on spontaneous incidence or primary tumor growth are less common (but do occur occasionally (18-21)). In mouse models of breast $(22)$ and prostate carcinomas $(16,17)$, as well as malignant melanoma $(23,24)$ and leukemia $(25,26), \beta$-adrenergic antagonists have been found to block stress-induced enhancement of tumor progression/metastasis without affecting primary tumor growth in vivo or tumor cell proliferation in vitro. $\beta$-adrenergic agonists have also been found accelerate in vivo tumor progression and metastasis in the absence of stress $(16,17,22,27)$. 
Several cellular and molecular processes have been found to mediate $\beta$-adrenergic influences on tumor progression (Figure 1), including recruitment of macrophages into the primary tumor (22), increased expression of pro-inflammatory cytokines such as IL-6 and IL-8 by tumor cells (28-30) and immune cells (29), VEGF-mediated increases in angiogenesis $(27,31,32)$, matrix metalloproteinase-related increases in tissue invasion (31, $33,34)$, tumor cell mobilization and motility $(17,35,36)$, FAK-mediated resistance to anoikis/apoptosis (37), BAD-mediated resistance to chemotherapy-induced apoptosis (16, 38). $\beta$-antagonists alone or in conjunction with non-steroidal anti-inflammatory agents (NSAIDs) have also been found to inhibit surgery-induced metastasis in animal models (24, $39,40)$. Some evidence suggests that $\beta$-adrenergic signaling can also inhibit p53-mediated DNA repair (41), suppress cytotoxic T lymphocyte and NK cell responses (26), inhibit expression of Type I interferons $(22,42)$, upregulate the Her2 signaling pathway $(43,44)$, stimulate arachadonic acid signaling (45), activate gene expression by tumor-promoting viruses $(9,46)$, and upregulate the SNAI2 transcription factor regulating epithelialmesenchymal transition (S. Cole, S. Lutgendorf, and A. Sood, unpublished data). Each of these dynamics may contribute to SNS-induced tumor progression in vivo, but has not yet been confirmed to do so in direct inhibitor studies of mediation. However, it is clear that SNS activation can regulate a wide range of cancer-related molecular pathways via both direct regulation of $\beta$-receptor-bearing tumor cells and regulation of other $\beta$-receptor-bearing cells present in the tumor microenvironment such as macrophages and vascular cells.

The SNS can potentially regulate tumor $\beta$-adrenergic signaling both via circulating NE/E and via local NE release from SNS nerve fibers. However, growing evidence suggests the later dynamic plays a dominant role. Analyses of catecholamine levels in human ovarian carcinomas document substantially higher NE levels in tumor tissue than in blood, and they find no detectable $\mathrm{E}$ in tumor tissue (as would be expected if blood were the primary source of tumor catecholamines) $(47,48)$. Intra-tumor NE levels also correlate with patient psychosocial risk factors and with tumor gene expression profiles, but blood levels of NE/E do not $(47,48)$. Both observations suggest a primary role for local nerve fiber-derived $\mathrm{NE}$ in driving $\beta$-adrenergic effects on tumor biology. Histological analyses of catecholaminergic fibers within human breast and ovarian carcinomas show extensive peri-vascular innervation and occasional radiation of nerve fibers into the tumor parenchyma (29)(E. Sloan, unpublished data). This pattern of SNS innervation is similar to that observed in other solid tissues (e.g., lymph nodes (49)) and provides a source of NE to directly regulate $\beta$ adrenergic receptors on both tumor cells and stromal cells (particularly tumor-associated macrophages (22)). Interestingly, data from the lymph node setting have shown that chronic stress can increase the density of SNS nerve fibers within parenchymal tissue (49). Activated macrophages may also synthesize catecholamines (50), but no evidence has yet shown this to occur within tumors. An additional pathway by which SNS activity may regulate cancer biology both within the primary tumor microenvironment and systemically at metastatic target sites involves $\beta$-adrenergic regulation of myelopoiesis (51-55) and its effects on monocyte/macrophage trafficking and gene expression $(22,52,55)$. This implies that some $\beta$-adrenergic influences on tumor biology may originate outside the tumor, via SNS innervation of the bone marrow hematopoietic environment or catecholamine "conditioning" of trafficking monocytes that are ultimately recruited into the tumor microenvironment (22). Such dynamics would complicate the targeting of therapeutic interventions based on tumor tissue $\beta$-receptor expression, but they also imply that adjuvant therapy with $\beta$-antagonists may suppress systemic support for tumor progression.

\section{Clinical-Translational Advances}

Because $\beta$-adrenergic signaling modulates tumor progression via multiple downstream molecular pathways, $\beta$ antagonists may provide a highly-leveraged adjuvant therapy strategy 
with pleiotropic impacts on the primary tumor, its surrounding microenvironment, and metastatic target sites. The biological appeal of this concept is enhanced by the widespread availability of safe, inexpensive, and well-understood $\beta$ antagonists (4). However, several issues need to be resolved in order to establish the translational potential of $\beta$-blockers as adjuvant therapy for cancer.

The most pressing need involves direct assessment of $\beta$ antagonists' clinical efficacy in randomized Phase II trials. Conflicting results from currently available non-randomized observational studies $(11-15,56)$ suggest that further observational studies are not likely to definitively establish $\beta$-blockers' clinical utility in cancer due to methodologic difficulties such as, 1.) confounding by indication (e.g., the primary historical indication for $\beta$-blockade, cardiovascular disease, shares common pathophysiologic drivers with cancer progression such as smoking, adiposity, and systemic inflammation), 2.) confounding with other pharmacologic exposures that may affect cancer progression (e.g., ACE inhibitors), 3.) absence of information on influential risk factors and treatment parameters (e.g., cardiovascular datasets provide limited information on cancer progression/mortality risk factors, and cancer-related datasets provide limited measures of $\beta$-blocker agents/ utilization), and, 4.) time- and practice pattern-related confounding of cancer survival trends with $\beta$-blocker utilization trends (particularly for non-selective $\beta$-antagonists which are most likely to be efficacious as outlined below). Randomized controlled trials provide the only certain way to overcome such biases and definitively assess $\beta$-antagonists' protective effects on clinical cancer progression. The availability of pre-clinical data and approved, safe, and inexpensive $\beta$-antagonists with well-understood pharmacology and minimal side-effects provide a favorable risk/benefit profile for initial Phase II proof-of-concept trials in clinical oncology.

Clinical trial initiation will require selection of optimal disease settings and treatment regimens for assessing clinical impact. Preclinical laboratory models and human pharmacoepidemiologic studies both suggest that $\beta$-antagonists are likely to be most effective in inhibiting the micro-metastatic spread of early-stage tumors, as opposed to chemoprevention of new tumors or reduction of advanced tumor burdens. As such, it makes sense to target tumor types such as breast or prostate cancer that are routinely detected at early stage, metastasize via inflammatory and circulatory mechanisms already linked to $\beta$-adrenergic signaling, and are sufficiently prevalent to provide high-power detection of group differences amidst the low progression/recurrence rates characteristic of early stage disease. In the context of breast cancer, some epidemiologic data suggest that $\beta$-antagonists may be particularly valuable in the context of ER-/PR-/Her2- "triple negative breast cancer" (TNBC) (13). Initial trials should also target disease settings such as ovarian carcinoma and malignant melanoma for which extensive pre-clinical or pharmaco-epidemiologic data already exist and suggest a significant therapeutic potential.

Optimal $\beta$-antagonist regimens also need to be defined, including the specific agent, the timing of its initiation, and the duration of treatment. Pharmacologic dissection of preclinical models of ovarian, breast, and prostate cancer find SNS effects to be mediated predominately by $\beta_{2}$ - or $\beta_{3}$-adrenergic receptors $(16,19,27,55)$. Non-selective $\beta$-antagonists such as Propranolol and Nadolol have been highly active in these model systems, but the more commonly prescribed $\beta_{1}$-selective agents such as Atenolol generally failed to inhibit SNS effects on tumor progression. Similar effects have been observed in pharmacoepidemiologic analyses of breast cancer, with non-selective $\beta$-antagonists showing comparable (13) or greater protective effects than $\beta_{1}$-selective agents (12). Given these observations, the use of non-selective antagonists such as Propranolol would provide the broadest biological leverage and minimize the risk of missing an active $\beta$-receptor target. CNS adrenergic receptors appear to play a role in some protective effects of $\beta$-antagonists, 
suggesting that CNS-penetrant agents such as Propranolol may be preferred over agents that do not cross the blood-brain-barrier such as Nadolol. Experimental data showing that $\beta$ antagonist inhibition of surgery-induced metastasis $(24,39,40)$ suggest initiation prior to surgery (i.e., neo-adjuvant) and perhaps in combination with an NSAID. The duration of $\beta$ blockade required to reduce tumor progression/recurrence rates has not been determined, but long-term $\beta$-blockade has routinely been used in cardiology and would seem to provide an appropriate starting point in oncology.

$\beta$-blocker treatment could potentially be targeted based on tumor characteristics such as the expression of $\beta$-receptors (57) or their downstream target genes (48), or based on patient characteristics such as stress or anxiety levels $(9,58,59)$. However, there is currently no evidence that any patient- or tumor-level characteristics affect $\beta$-blocker efficacy in clinical oncology. As such, initial RCTs should target the general disease settings in which $\beta$ blockade is likely to be most effective (as outlined above) and collect additional patient- and tumor-specific data to support responder analyses identifying predictive biomarkers of treatment efficacy. There are several reasons why tumor $\beta$-receptor expression might not provide an accurate predictive biomarker, including the fact that receptor expression does not assess the amount of SNS NE/E ligand impinging upon the receptor and potential adrenergic effects at extra-tumoral sites such as metastatic target tissues or the bone marrow hematopoietic generation of subsequently infiltrating macrophages and lymphocytes (22, $60)$.

Although a variety of translational parameters remain to be optimized, a growing body of pre-clinical and pharmaco-epidemiologic data suggest that $\beta$-adrenergic antagonists hold considerable promise for inhibiting the pleiotropic effects of SNS activation on tumor progression and metastasis. Over the next few years, we can expect further data expanding the range of tumor types examined, identifying additional mechanisms of $\beta$-adrenergic effects on tumor progression, and initial RCTs assessing the efficacy of $\beta$-blockade as an adjuvant therapy in clinical oncology.

\section{Acknowledgments}

Space constraints have necessitated the omission of many relevant references. Preparation of this review was supported by NIH grants CA116778 and CA109298.

\section{References}

1. Weiner, H. Perturbing the Organism: The Biology of Stressful Experience. Chicago: University of Chicago Press; 1992.

2. Sapolsky, RM. Why zebras don't get ulcers: A guide to stress, stress-related diseases, and coping. New York: Freeman; 1994.

3. Daly CJ, McGrath JC. Previously unsuspected widespread cellular and tissue distribution of betaadrenoceptors and its relevance to drug action. Trends Pharmacol Sci. 2011; 32:219-226. [PubMed: 21429599]

4. Baker JG, Hill SJ, Summers RJ. Evolution of beta-blockers: from anti-anginal drugs to liganddirected signalling. Trends Pharmacol Sci. 2011; 32:227-234. [PubMed: 21429598]

5. Montminy M. Transcriptional regulation by cyclic AMP. Annu Rev Biochem. 1997; 66:807-822. [PubMed: 9242925]

6. Zhang X, Odom DT, Koo SH, Conkright MD, Canettieri G, Best J, et al. Genome-wide analysis of cAMP-response element binding protein occupancy, phosphorylation, and target gene activation in human tissues. Proc Natl Acad Sci U S A. 2005; 102:4459-4464. Epub 2005 Mar 4457. [PubMed: 15753290] 
7. Luttrell LM, Ferguson SS, Daaka Y, Miller WE, Maudsley S, Della Rocca GJ, et al. Beta-arrestindependent formation of beta2 adrenergic receptor-Src protein kinase complexes. Science. 1999; 283:655-661. [PubMed: 9924018]

8. de Rooij J, Zwartkruis FJ, Verheijen MH, Cool RH, Nijman SM, Wittinghofer A, et al. Epac is a Rap1 guanine-nucleotide-exchange factor directly activated by cyclic AMP. Nature. 1998; 396:474477. [PubMed: 9853756]

9. Antoni MH, Lutgendorf SK, Cole SW, Dhabhar FS, Sephton SE, McDonald PG, et al. The influence of bio-behavioural factors on tumour biology: pathways and mechanisms. Nat Rev Cancer. 2006; 6:240-248. [PubMed: 16498446]

10. Chida Y, Hamer M, Wardle J, Steptoe A. Do stress-related psychosocial factors contribute to cancer incidence and survival? Nat Clin Pract Oncol. 2008; 5:466-475. Epub 2008 May 2020. [PubMed: 18493231]

11. Powe DG, Voss MJ, Zanker KS, Habashy HO, Green AR, Ellis IO, et al. Beta-blocker drug therapy reduces secondary cancer formation in breast cancer and improves cancer specific survival. Oncotarget. 2010; 1:628-638. [PubMed: 21317458]

12. Barron TI, Connolly RM, Sharp L, Bennett K, Visvanathan K. Beta blockers and breast cancer mortality: a population- based study. J Clin Oncol. 2011; 29:2635-2644. [PubMed: 21632503]

13. Melhem-Bertrandt A, Chavez-Macgregor M, Lei X, Brown EN, Lee RT, Meric-Bernstam F, et al. Beta-blocker use is associated with improved relapse-free survival in patients with triple-negative breast cancer. J Clin Oncol. 2011; 29:2645-2652. [PubMed: 21632501]

14. De Giorgi V, Grazzini M, Gandini S, Benemei S, Lotti T, Marchionni N, et al. Treatment with beta-blockers and reduced disease progression in patients with thick melanoma. Arch Intern Med. 2011; 171:779-781. [PubMed: 21518948]

15. Lemeshow S, Sorensen HT, Phillips G, Yang EV, Antonsen S, Riis AH, et al. Beta-Blockers and Survival among Danish Patients with Malignant Melanoma: A Population-Based Cohort Study. Cancer Epidemiol Biomarkers Prev. 2011; 20:2273-2279. [PubMed: 21933972]

16. Kulik, GA.; Hassan, S.; Karpova, Y.; Baurin, V. Behavioral stress protects prostate cancer cells from apoptosis. Proceedings of the 102nd Annual Meeting of the American Association for Cancer Research; 2011 Apr 2-6; Orlando, Florida. 2011.

17. Palm D, Lang K, Niggemann B, Drell TLt, Masur K, Zaenker KS, et al. The norepinephrine-driven metastasis development of PC-3 human prostate cancer cells in BALB/c nude mice is inhibited by beta-blockers. Int J Cancer. 2006; 118:2744-2749. [PubMed: 16381019]

18. Hermes GL, Delgado B, Tretiakova M, Cavigelli SA, Krausz T, Conzen SD, et al. Social isolation dysregulates endocrine and behavioral stress while increasing malignant burden of spontaneous mammary tumors. Proc Natl Acad Sci U S A. 2009; 106:22393-22398. [PubMed: 20018726]

19. Cao L, Liu X, Lin EJ, Wang C, Choi EY, Riban V, et al. Environmental and genetic activation of a brain-adipocyte BDNF/leptin axis causes cancer remission and inhibition. Cell. 2010; 142:52-64. [PubMed: 20603014]

20. Boyd AL, Salleh A, Humber B, Yee J, Tomes L, Kerr LR. Neonatal experiences differentially influence mammary gland morphology, estrogen receptor $\{$ alpha $\}$ protein levels, and carcinogenesis in BALB/c mice. Cancer Prev Res (Phila). 2010; 3:1398-1408. [PubMed: 21084260]

21. Schuler LA, Auger AP. Psychosocially influenced cancer: diverse early-life stress experiences and links to breast cancer. Cancer Prev Res (Phila). 2010; 3:1365-1370. [PubMed: 21084258]

22. Sloan EK, Priceman SJ, Cox BF, Yu S, Pimentel MA, Tangkanangnukul V, et al. The sympathetic nervous system induces a metastatic switch in primary breast cancer. Cancer Res. 2010; 70:70427052. [PubMed: 20823155]

23. Hasegawa H, Saiki I. Psychosocial stress augments tumor development through beta-adrenergic activation in mice. Jpn J Cancer Res. 2002; 93:729-735. [PubMed: 12149137]

24. Goldfarb Y, Sorski L, Benish M, Levi B, Melamed R, Ben-Eliyahu S. Improving postoperative immune status and resistance to cancer metastasis: a combined perioperative approach of immunostimulation and prevention of excessive surgical stress responses. Ann Surg. 2011; 253:798-810. [PubMed: 21475023] 
25. Lamkin DM, Sloan EK, Patel AJ, Chiang BS, Pimentel MA, Ma JCY, et al. Chronic stress enhances progression of acute lymphoblastic leukemia via beta-adrenergic signaling. 2011 Under review.

26. Inbar S, Neeman E, Avraham R, Benish M, Rosenne E, Ben-Eliyahu S. Do stress responses promote leukemia progression? An animal study suggesting a role for epinephrine and prostaglandin-E2 through reduced NK activity. PLoS One. 2011; 6:e19246. [PubMed: 21559428]

27. Thaker PH, Han LY, Kamat AA, Arevalo JM, Takahashi R, Lu C, et al. Chronic stress promotes tumor growth and angiogenesis in a mouse model of ovarian carcinoma. Nat Med. 2006; 12:939944. Epub 2006 Jul 2023. [PubMed: 16862152]

28. Nilsson MB, Armaiz-Pena G, Takahashi R, Lin YG, Trevino J, Li Y, et al. Stress hormones regulate interleukin-6 expression by human ovarian carcinoma cells through a Src-dependent mechanism. J Biol Chem. 2007; 282:29919-29926. Epub 22007 Aug 29923. [PubMed: 17716980]

29. Cole S, Arevalo J, Takahashi R, Sloan EK, Lutgendorf S, Sood AK, et al. Computational identification of gene-social environment interaction at the human IL6 locus. Proc Natl Acad Sci U S A. 2010; 107:5681-5686. [PubMed: 20176930]

30. Shahzad MM, Arevalo JM, Armaiz-Pena GN, Lu C, Stone RL, Moreno-Smith M, et al. Stress effects on FosB- and interleukin-8 (IL8)-driven ovarian cancer growth and metastasis. J Biol Chem. 2010; 285:35462-35470. [PubMed: 20826776]

31. Yang EV, Sood AK, Chen M, Li Y, Eubank TD, Marsh CB, et al. Norepinephrine up-regulates the expression of vascular endothelial growth factor, matrix metalloproteinase (MMP)-2, and MMP-9 in nasopharyngeal carcinoma tumor cells. Cancer Res. 2006; 66:10357-10364. [PubMed: 17079456]

32. Chakroborty D, Sarkar C, Basu B, Dasgupta PS, Basu S. Catecholamines regulate tumor angiogenesis. Cancer Res. 2009; 69:3727-3730. [PubMed: 19383906]

33. Landen CN Jr, Lin YG, Armaiz Pena GN, Das PD, Arevalo JM, Kamat AA, et al. Neuroendocrine modulation of signal transducer and activator of transcription-3 in ovarian cancer. Cancer Res. 2007; 67:10389-10396. [PubMed: 17974982]

34. Sood AK, Bhatty R, Kamat AA, Landen CN, Han L, Thaker PH, et al. Stress hormone-mediated invasion of ovarian cancer cells. Clin Cancer Res. 2006; 12:369-375. [PubMed: 16428474]

35. Lang K, Drell TLt, Lindecke A, Niggemann B, Kaltschmidt C, Zaenker KS, et al. Induction of a metastatogenic tumor cell type by neurotransmitters and its pharmacological inhibition by established drugs. Int J Cancer. 2004; 112:231-238. [PubMed: 15352035]

36. Drell, TLt; Joseph, J.; Lang, K.; Niggemann, B.; Zaenker, KS.; Entschladen, F. Effects of neurotransmitters on the chemokinesis and chemotaxis of MDA-MB-468 human breast carcinoma cells. Breast Cancer Res Treat. 2003; 80:63-70. [PubMed: 12889599]

37. Sood AK, Armaiz-Pena GN, Halder J, Nick AM, Stone RL, Hu W, et al. Adrenergic modulation of focal adhesion kinase protects human ovarian cancer cells from anoikis. J Clin Invest. 2010; 120:1515-1523. [PubMed: 20389021]

38. Sastry KS, Karpova Y, Prokopovich S, Smith AJ, Essau B, Gersappe A, et al. Epinephrine protects cancer cells from apoptosis via activation of cAMP-dependent protein kinase and BAD phosphorylation. J Biol Chem. 2007; 282:14094-14100. [PubMed: 17353197]

39. Glasner A, Avraham R, Rosenne E, Benish M, Zmora O, Shemer S, et al. Improving survival rates in two models of spontaneous postoperative metastasis in mice by combined administration of a beta-adrenergic antagonist and a cyclooxygenase-2 inhibitor. J Immunol. 2010; 184:2449-2457. [PubMed: 20124103]

40. Lee JW, Shahzad MM, Lin YG, Armaiz-Pena G, Mangala LS, Han HD, et al. Surgical stress promotes tumor growth in ovarian carcinoma. Clin Cancer Res. 2009; 15:2695-2702. [PubMed: 19351748]

41. Hara MR, Kovacs JJ, Whalen EJ, Rajagopal S, Strachan RT, Grant W, et al. A stress response pathway regulates DNA damage through beta2-adrenoreceptors and beta-arrestin-1. Nature. 2011; 477:349-353. [PubMed: 21857681]

42. Collado-Hidalgo A, Sung C, Cole S. Adrenergic inhibition of innate anti-viral response: PKA blockade of Type I interferon gene transcription mediates catecholamine support for HIV-1 replication. Brain Behav Immun. 2006; 20:552-563. Epub 2006 Feb 2028. [PubMed: 16504464] 
43. Shi M, Liu D, Duan H, Qian L, Wang L, Niu L, et al. The beta2-adrenergic receptor and Her2 comprise a positive feedback loop in human breast cancer cells. Breast Cancer Res Treat. 2011; 125:351-362. [PubMed: 20237834]

44. Gu L, Lau SK, Loera S, Somlo G, Kane SE. Protein kinase A activation confers resistance to trastuzumab in human breast cancer cell lines. Clin Cancer Res. 2009; 15:7196-7206. [PubMed: 19920112]

45. Cakir Y, Plummer HK 3rd, Tithof PK, Schuller HM. Beta-adrenergic arachidonic acid-mediated growth regulation of human breast cancer cell lines. Int J Oncol. 2002; 21:153-157. [PubMed: 12063562]

46. Chang M, Brown H, Collado-Hidalgo A, Arevalo J, Galic Z, Symensma T, et al. Betaadrenoreceptors reactivate KSHV lytic replication via PKA-dependent control of viral RTA. Journal of Virology. 2005

47. Lutgendorf SK, Degeest K, Dahmoush L, Farley D, Penedo F, Bender D, et al. Social isolation is associated with elevated tumor norepinephrine in ovarian carcinoma patients. Brain Behav Immun. 2011

48. Lutgendorf SK, Degeest K, Sung CY, Arevalo JM, Penedo F, Lucci J 3rd, et al. Depression, social support, and beta-adrenergic transcription control in human ovarian cancer. Brain Behav Immun. 2009; 23:176-183. [PubMed: 18550328]

49. Sloan EK, Capitanio JP, Tarara RP, Mendoza SP, Mason WA, Cole SW. Social stress enhances sympathetic innervation of primate lymph nodes: mechanisms and implications for viral pathogenesis. J Neurosci. 2007; 27:8857-8865. [PubMed: 17699667]

50. Flierl MA, Rittirsch D, Nadeau BA, Chen AJ, Sarma JV, Zetoune FS, et al. Phagocyte-derived catecholamines enhance acute inflammatory injury. Nature. 2007; 449:721-725. Epub 2007 Sep 2030. [PubMed: 17914358]

51. Cohen MJ, Shankar R, Stevenson J, Fernandez R, Gamelli RL, Jones SB. Bone marrow norepinephrine mediates development of functionally different macrophages after thermal injury and sepsis. Ann Surg. 2004; 240:132-141. [PubMed: 15213629]

52. Engler H, Bailey MT, Engler A, Sheridan JF. Effects of repeated social stress on leukocyte distribution in bone marrow, peripheral blood and spleen. J Neuroimmunol. 2004; 148:106-115. [PubMed: 14975591]

53. Laakko T, Fraker P. Rapid changes in the lymphopoietic and granulopoietic compartments of the marrow caused by stress levels of corticosterone. Immunology. 2002; 105:111-119. [PubMed: 11849321]

54. Tang Y, Shankar R, Gamboa M, Desai S, Gamelli RL, Jones SB. Norepinephrine modulates myelopoiesis after experimental thermal injury with sepsis. Ann Surg. 2001; 233:266-275. [PubMed: 11176134]

55. Cole, SW. Beta-adrenergic regulation of gene expression in cancer. Proceedings of the 102nd Annual Meeting of the American Association for Cancer Research; 2011 Apr 2-6; Orlando, Florida. 2011.

56. Shah SM, Carey IM, Owen CG, Harris T, Dewilde S, Cook DG. Does beta-adrenoceptor blocker therapy improve cancer survival? Findings from a population-based retrospective cohort study. $\mathrm{Br}$ J Clin Pharmacol. 2011; 72:157-161. [PubMed: 21453301]

57. Powe DG, Voss MJ, Habashy HO, Zanker KS, Green AR, Ellis IO, et al. Alpha-and betaadrenergic receptor (AR) protein expression is associated with poor clinical outcome in breast cancer: an immunohistochemical study. Breast Cancer Res Treat. 2011

58. Antoni MH, Lutgendorf SK, Blomberg B, Stagl J, Carver CS, Lechner S, et al. Transcriptional modulation of human leukocytes by cognitive-behavioral stress management in women undergoing treatment for breast cancer. Biological Psychiatry. 2011 in press.

59. Lutgendorf SK, Sood AK, Antoni MH. Host factors and cancer progression: Biobehavioral signaling pathways and interventions. J Clin Oncol. 2010 in press.

60. Lutgendorf SK, Lamkin DM, Jennings NB, Arevalo JM, Penedo F, DeGeest K, et al. Biobehavioral influences on matrix metalloproteinase expression in ovarian carcinoma. Clin Cancer Res. 2008; 14:6839-6846. [PubMed: 18980978] 


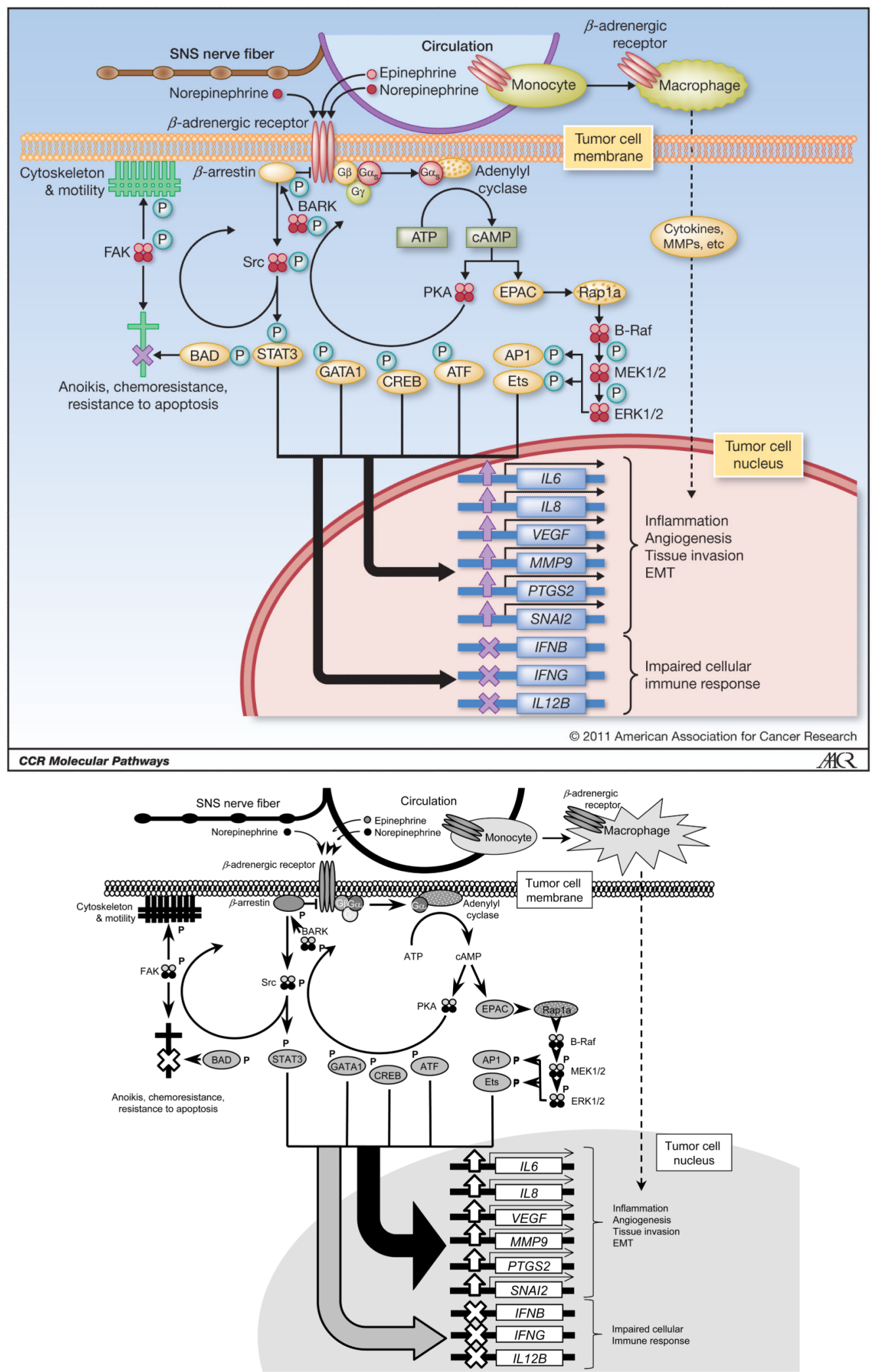

Figure 1. The $\beta$-adrenergic signaling pathway in cancer

Clin Cancer Res. Author manuscript; available in PMC 2013 March 1. 
Sympathetic nervous system (SNS) fight-or-flight stress responses deliver epinephrine (E) and norepinephrine (NE) into the tumor microenvironment via circulating blood and $\mathrm{NE}$ release from local sympathetic nerve fibers. Both catecholamines bind to $\beta$-adrenergic receptors, resulting in Gas-mediated activation of adenylyl cyclase, and subsequent conversion of adenosine triphosphate (ATP) into cyclic $3^{\prime}-5^{\prime}$ adenosine monophosphate (cAMP). Transient flux of interacellular cAMP activates two major biochemical effector systems. (1) cAMP activates protein kinase A (PKA) to phosphorylate multiple target proteins including transcription factors of the CREB/ATF and GATA families, as well as the $\beta$-adrenergic receptor kinase (BARK). BARK recruitment of $\beta$-arrestin inhibits $\beta$-adrenergic receptor signaling and activates Src kinase, resulting in activation of transcription factors such as STAT3 and downstream kinases such as focal adhesion kinase (FAK). FAK activation modulates cell trafficking and motility via cytoskeletal dynamics, as well as cellular resistance to apoptosis (e.g., anoikis). PKA-dependent activation of Bcl-2 family member BAD can also render cancer cells resistant to chemotherapy-induced apoptosis. (2) In the second major effector pathway, cAMP activation of the Exchange Protein activated by Adenylyl Cyclase (EPAC) leads to Rap1A-mediated activation of the B-Raf/MAP kinase signaling pathway and downstream effects on diverse cellular processes including gene transcription mediated by AP-1 and Ets family transcription factors. The general pattern of transcriptional responses induced by $\beta$-adrenergic signaling includes up-regulated expression of metastasis-associated genes involved in inflammation, angiogenesis, tissue invasion, and epithelial-mesenchymal transition, and down-regulated expression of genes facilitating anti-tumor immune responses. In addition to direct effects on $\beta$-receptor-bearing tumor cells, SNS activation also modulates cancer biology by regulating the bone marrow generation and tumor recruitment and transcriptional activation of $\beta$-receptor-bearing monocyte/macrophages, as well as the growth and differentiation of vascular endothelial cells and pericytes. $\beta$-adrenergic effects on stromal cells in the tumor microenvironment generally synergize with direct effects on tumor cells in promoting cancer survival, growth, and metastatic dissemination. 